\title{
Cytogenetic an Experimental Monitoring Test for Plant Extracts
}

\author{
Dhamraa W. AL-Dulaimi, Sarah F. Faisal, Hussein M. Baharetha, \\ Amin Malik Shah Abdul Majid * \\ EMAN Testing \& Research Laboratory, Department of Pharmacology, School of Pharmaceutical Sciences, \\ Universiti Sains Malaysia, Minden 11800, Pulau Pinang, Malaysia.
}

\begin{abstract}
More than two centuries have been passed since the chromosomes have been firstly observed in plant cells by Nageli in 1842. During this long period, chromosomes have been discovered in human cells and well recognized as a source of genes locations. The effects of chemicals and environmental pollution in human health and caners became an interested field of studying diver mutagens and their role in affecting the genetic materials. Cytogenetic tests were the main tools to evaluate the effects of those mutagens on human genome and chromosomes. Many techniques have been used for these purposes including in vitro and in vivo analyzing tests using human and animal cells. The intent of this article is to review the role of cytogenetic techniques in detecting the effects of mutagens on chromosomal aberrations and the role of plant extracts in monitoring these effects.
\end{abstract}

Keywords: Cytogenetic analysis mutagens, chromosomes, human genome, gene, cancer and plant extracts

\section{Brief History}

Cytogenetic mainly concerned in studying chromosomes that were first observed in plant cells by Karl Wilhelm von Nageli at 1842 (Dixit, Potaliya, \& Dixit, 2015). Walther Flemming at 1882 discovered Mitosis using salamander cells. (Mitchison \& Salmon, 2001) Chromosomes named by von Waldeyer in 1888. The correct chromosome number in humans (46) was determined in 1956 by Tjio and Levan. Prior to this date, the normal human chromosomes numbers was considered as 48 (Li, Xu, \& Shu, 2016). With this invention, the certain congenital defects showed to be associated with certain chromosome defect. Human cytogenetic became an interested field of study when the techniques of preparing chromosomes have been developed during the few decades. Earlier in $20^{\text {th }}$ century, the set chromosomes (karyotype) appreciated as a gene carrier, where the next step of development that took a place. In 1959 Lejeune, et al., described the first chromosome abnormality associated with a clinical syndrome, trisomy 21 in the Down syndrome (Jiménez et al., 2016). Caspersson developed banding techniques, which differentially stain chromosomes. This allows chromosomes of equal size to be differentiated as well as to elucidate the breakpoints and constituent chromosomes involved in chromosome translocations (Gold, Li, Shipley, \& Powers, 1990). With the advent of chromosome banding techniques in the 1970s, it was possible to identify with certainty all chromosome pairs and to characterize more accurately abnormalities of chromosome number and structure.

For a given banding technique, each chromosome pair exhibits a unique pattern of differential staining along the length of the chromosome. By the early 1960s, Ideograms or the diagram was used to identify the chromosomes based on the banding patterns that became the basis for both prenatal and oncological cytogenetic fields, and quickly moved into the clinical lab where karyotyping allowed scientists to look for chromosomal alterations (Shaffer, McGowan- Jordan, \& Schmid, 2013)

\section{Role of Cytogenetic In Medicine}

Cytogenetic has become an exciting and dynamic field of study that analyses the number and structure of human and animal chromosomes. Any changes that affect the number and/or structure of the chromosomes can cause complications with growth, development, and the body functions. Chromosomal abnormalities can occur early during fetal development when egg and sperm cells are being made or after birth in any cell in the body, which can disrupt genes, causing the proteins made from these disrupted genes to be missing or faulty. The size, location and timing of the structural or numerical changes in chromosomes can lead to birth defects such as Down syndrome (trisomy 21), Patau syndrome (trisomy13) and trisomy 18) and Edwards syndrome (Palomaki et al., 2012). Or it may affect a single gene within the chromosomes like PKU (phenylketonuria) caused by abnormal PHA gene on chromosome 12 cause malfunction of phenylalanine hydroxylase (PHA) enzyme that breaks down the amino acid phenylalanine (Schaaf, Zschocke, \& Potocki, 2011). Nowadays, the diagnosis and treatment of several leukaemia's and lymphomas, as well as some solid tumours, depends heavily on cytogenetic analysis of specific chromosomal aberrations, which are consistently observed in these particular cancers. Currently, it is estimated that no fewer than 1 million cytogenetic and molecular cytogenetic 
analyses are performed per year representing the standard of care in several fields of medicine and the routine clinical workup for numerous patients suffering from congenital malformations, mental diseases, cancers, or reproductive problems (Sheth et al., 2014).

\section{Role of cytogenetic test in monitoring environmental risk}

In recent few years, chromosomal aberrations (CA) are one of the important biological consequences of human exposure to ionizing radiation and other genotoxic agents. In epidemiological studies, it has been shown that people with elevated frequencies of CA in their peripheral blood lymphocytes have a significantly-elevated risk of developing cancer (Vodenkova et al., 2015). The first medical case of occupational cancer was reported in 1775 by Percival Pott, who described scrotal cancer among British chimney sweeps. However, it was not until more than 150 years later when benzo (a) pyrene was identified as the probable causative agent in chimney soot (Balmain \& Yuspa, 2014). Hundreds of chemicals are capable of inducing cancer in humans or animals after prolonged or excessive exposure. There are many well-known examples of chemicals that can cause cancer in humans. The fumes of the metals cadmium, nickel, and chromium are known to cause lung cancer (Purushothaman, Reghu, \& Vijayan, 2015). Vinyl chloride causes liver sarcomas (Chaudhary, Bhadana, Singh, \& Ahuja, 2015). Exposure to arsenic increases the risk of skin and lung cancer (Screening \& Board, 2015). Leukemia can result from chemically induced changes in bone marrow from exposure to benzene and cyclophosphamide, among other toxicants (Persano, Zagoura, Louisse, \& Pistollato, 2015). Other chemicals, including benzo[a]pyrene and ethylene dibromide, are considered by authoritative scientific organizations to be probably carcinogenic in humans because they are potent carcinogens in animals. Chemically-induced cancer generally develops many years after exposure to a toxic agent. A latency period of as much as thirty years has been observed between exposure to asbestos, for example, and incidence of lung cancer (Lin, Chang, Wang, \& Lee, 2015). Some other chemicals used to treat cancer showed to induce chromosomal aberrations.

\section{Role of plant and their extracts as chemo-preventive agents}

The use of plant based natural products as chemo-preventive agents is drawing a lot of attention and considered to be practically beneficial in certain cell/tissue based systems and animal model systems (Singh, Siddiqui, El- Abd, Mukhtar, \& Ahmad, 2016). It is necessary to provide scientific proof to justify the use of a plant or its active principles for medicinal purposes. Modern drugs, plants and plant extracts must be characterized after their pharmacological screening for their pharmacokinetic and pharmacodynamics properties, including toxicity. Cancer chemoprevention is defined as the use of chemicals or dietary components to block, inhibit, or reverse the development of cancer in normal or pre-neoplastic tissue.

A large number of potential chemo-preventive agents have been identified, and they function by mechanisms directed at all major stages of carcinogenesis (Oga, Sekine, Shitara, \& Horie, 2015). Recent focus of cancer chemoprevention is on intermediate biomarkers capable of detecting early changes that can be correlated with inhibition of carcinogenic progression. Many plant extract have proven to be a good cancer preventive agents through their abilities to modulates progress and abnormal cell cycle in cancer cell lines or to act as anti-angiogenic agents. Recent reports suggest that about one third of most common cancers in highincome country can be prevented by healthy plant-based diet (SERT ZAYIF \& UZ, 2016). Short-term tests such as the AMES test, mouse bone marrow micronucleus assay (e Silva et al., 2015) and chromosomal aberration analysis, are widely used systems in the detection and evaluation of anti-mutagens and anti-carcinogens (Apak, Özyürek, Guclu, \& Capanoglu, 2015). The use of plant-based medicines is believed to date back to prehistoric medicine (Ngulde, Sandabe, \& Hussaini, 2015). Historically, thousands of different species of plant have been reported as being useful for the treatment of cancer. In the 1950s, modern medicine began more systematically examining natural organisms as a source of useful anti-cancer substances (Zulkipli, David, Rajabalaya, \& Idris, 2015). There can be many years between promising laboratory work and the availability of an effective anticancer drug: Monroe Eliot Wall discovered anti-cancer properties in Camptotheca in 1958, but it was not until 1996 after further research and rounds of clinical trials that a derived drug was approved for use by the US Food and Drug Administration (SRINIVASAN, 2014 ). On the other side, herbal medicines can be potentially toxic to human health. In this way, scientific research has shown that many plants used in traditional and folk medicine are potentially toxic, mutagenic, and carcinogenic (Genuis, Schwalfenberg, Siy, \& Rodushkin, 2012) Nevertheless, some of them can cause adverse effects or have the potential to interact with other medications (Chen et al., 2012). However WHO (1971) and Committee 17 (1975) argued that a single test system is not sufficient to conclude that a particular agent is mutagenic or not. Therefore, further tests of these plants using mammalian test system were conducted (Celik, 2012).

\section{Bioactivities of plant extracts}

Numerous bioactive plant compounds, often referred to as nutraceuticals, have been recently tested for the potential clinical applications. Among the most frequently studied are resveratrol, a polyphenol presents in red- 
wine and grape-seed (Giovinazzo \& Grieco, 2015), epigallocatechin-3gallate (EGCG) from green tea (Hoffman, 2014) and curcumin from Curcuma longa. (Araujo \& Leon, 2001). It is also possible that components of other plants, including the constituents of local food diet may find application for modulation of carcinogenesis and angiogenesis, provided that their effectiveness will be confirmed in controlled scientifically validated trials (Milner, 2004). Angiogenesis is the process in which the new blood vessels are formed from pre-existing on (Lenzi, Bocci, \& Natale, 2016). The formation of new blood vessels from preexisting vascular network is a driving force of organ development in ontogeny, is necessary for ovulation and hair growth, and is prerequisite for proper wound healing. It is also a critical mechanism of numerous diseases, the most important of which are cancer and atherosclerosis. Therefore, modulation of angiogenesis is considered as therapeutic strategies of great importance for human health (Chhokar \& Tucker, 2003).

\section{Cytogenetic analysis}

Cytogenetic analysis is an in vitro clinical laboratory procedure for studying chromosomes and their abnormalities. Clinical cytogenetic is the study of chromosomes and their correlation to the phenotype (observable clinical characteristics). Certain clinical characteristics occur consistently in association with a particular chromosome abnormality (Munné, 2006). This phenotype-karyotype correlation is useful to the clinician in making a clinical genetic diagnosis and prognosis. There are two basic classes of chromosome aberrations: numeric and structural. Common abnormalities of chromosome number include aneuploidy, mosaicism, and polyploidy (Fragouli \& Delhanty, 2013). Numerical abnormalities turner syndrome which related to sexual development (XO), first identified in 1938 by Henry Turner and is now recognized as the most common sex-chromosome abnormality in women (Visscher, Metcalfe, \& Semple, 2015). Kleinfelter syndrome (XXY) is a sex chromosomal syndrome in males with an extra $\mathrm{X}$ chromosome $(47, \mathrm{XXY})$ the male sufferers of minimal testosterone production which leads to an abnormal body build (Cummins, Harrity, Walsh, \& Marron, 2015). Other numerical aberrations may lead to intellectual disability like, Down syndrome (trisomy 21) and fragile $\mathrm{X}$ in the Fragile $\mathrm{X}$ syndrome, which characterized by significantly impaired cognitive abilities (Valenti, de Bari, De Filippis, Henrion-Caude, \& Vacca, 2014). Trisomy 13, or Patau syndrome which characterized by multiple congenital anomalies and a poor prognosis with Congenital heart defects (Tal, Schwartz, Zolotushko, \& Lorber, 2014) Structural abnormalities include duplications, deletions, inversions and translocation (Escaramís, Docampo, \& Rabionet, 2015). It may include different malignant disorders like chromosome translocation between chromosome 9 and 22 which lead to chronic myeloid leukemia. It was the first consistent chromosomal abnormality associated with a specific type of leukemia (Casolari \& Melo, 2015). Recently, cytogenetic and molecular cytogenetic analyses are performed in several fields of medicine and the routine clinical workup for numerous patients suffering from congenital malformations, mental diseases, cancers, or reproductive problems (Vorsanova, Yurov, Soloviev, \& Iourov, 2010). Cytogenetic procedures may be used to study cell cycle associated phenomenon, gene clastogen challenge, chromosome breakage syndromes, chromosome fragile sites, and polymorphisms to monitor organ/tissue transplantation. The effect of many plant extracts on genetic material and chromosomes have been widely studied. Plant mutagenicity bioassays have been in existence for many years. Stadler reported the effect of chemical and physical agents on chromosomes in 1928 (Firbas \& Amon, 2014). Levan proposed in 1938 the first test on Allium (Adeyemo \& Farinmade, 2016).

\section{Experimental systems}

Cytogenetic tests analyze the frequency and types of chromosomal aberrations in mitotic cells and the frequency of micronuclei in interphase cells. Genotoxic agents cause DNA damage, which is either repaired or otherwise leads to alterations of the DNA. The detection of chromosomal damages could be either in vitro or in vivo using different methods including: micronucleus test and chromosomal aberration test.

\section{Micronucleus test}

The name means 'small nucleus' it is cytoplasmic bodies having a portion of acentric chromosome or whole chromosome which was not carried to the opposite poles during the anaphase. The test was firstly used to quantify chromosomal damage by H.J. Evans in1959. The test used in toxicological detection for potential genotoxic compounds and carcinogens that act by causing genetic damage. There are two major versions of this test, in vitro and in vivo. The in vitro micronucleus test detects genotoxic damage in interphase cells. The current methodologies and data for the in vitro micronucleus test were reviewed in 1999 during the second international workshop on genotoxicity testing (Kirsch-Volders et al., 2003). The in vivo test could be assessed using erythrocytes of blood, liver and lung tissues (Kang, Kwon, Lee, \& Seo, 2013). Mice bone marrow micronucleus test were studied in bone marrow erythroblast when developed into a polychromatic erythrocyte, any micronucleus that has been formed may remain behind in a nucleated cytoplasm (Balmus et al., 2015). According to the OECD guideline the typical cells used are human or rodent cells cultures. The cells should completed mitosis during the treatment or post treatment incubation period. The cytokinesis should be blocked 
by cytochalasin B that inhibit network formation by actin filaments and prevent separation of daughter cells after mitosis leading to formation of binucleated cells (Manshian, Singh, \& Doak, 2013).

\section{Chromosomal aberration test}

The chromosome aberration test is one of the sensitive methods to identify the structural or numerical abnormalities in mammalian chromosomes. Spontaneous and induced chromosome aberrations have been studied over more than a century (Natarajan, 2002). The test assessed in vitro and in vivo. The detection of structural chromosome aberrations usually tested in bone marrow cells of animals, usually rodents. Bone marrow is the target tissue in this test, since it is a highly vascularized tissue, and it contains a population of rapidly cycling cells that can be readily isolated and processed. Animals are exposed to the test substance by gavage using a stomach tube or by intraperitoneal injection, and sacrificed after appropriate time of treatment. Prior to sacrifice, animals are treated with a metaphase-arresting agent (usually used colchicine). Chromosome preparations are then made from the bone marrow cells and stained. Metaphase cells are analyzed for chromosome aberrations. Each treated and control group must include at least five analyzable animals per sex (Oecd, 1994). In vitro chromosomal aberration test was evaluated to identify agents that cause structural or numerical chromosomal aberrations in cultured mammalian cells. A variety of mammalian cell lines were used including human cells, Chinese hamster fibroblasts, human or other mammalian peripheral blood lymphocytes. Appropriate culture medium and incubation conditions like $\mathrm{CO}_{2}$ concentration, temperature and humidity should be used to maintain the cells. Human lymphocytes culture in heparinized blood or separated are added to suitable medium. The cell stimulated by mitogen to become mitotically active and incubated at $37^{\circ} \mathrm{C}$. The cells are exposed to the test substance in the presence or absence of an appropriate metabolic activation system. The metabolic activation is used with specific positive controls including (benzo (a) pyrene, cyclophosphamide). While other mutagens or positive controls that do not need metabolic activations are

(methyl methanesulfonate, ethyl methanesulfonate, ethylnitrosourea, mitomycin $\mathrm{C}$ and 4-nitroquinoline-Noxide). After appropriate time of incubation; the cells are harvested by adding a mitotic arresting agent colchicine or demecolicin. Cells are also harvested by centrifugations and incubation with hypotonic solution and fixed with suitable fixation and staining. Mitotic index used to measure cytotoxicity is acceptable for mixed cell cultures, such as whole blood cultures where peripheral lymphocytes are used as the genotoxic target cell. At least 200 well-spread metaphases should be scored per concentration and control to determine mitotic index and chromosomal aberrations. (Food \& Administration, 2000).

\section{Conclusion}

Based on the data provided in this review, it is concluded that cytogenetic tests were fast and sensitive assays to detect environmental genotoxic and mutagens as well as to evaluate the protective mechanisms of herbal preparations, plant extracts and phyto chemicals for protection against cytotoxicity in vitro and/or in vivo. For the possibility of assessing several genetic endpoints; these tests also enable to evaluate the action mechanisms of the tested agents on DNA and provides an important method for screening environmental contamination.

\section{Acknowledgements}

The authors would like to acknowledge the Institute of Postgraduate Studies at the Universiti Sains Malaysia for providing fellowship [(P-FM0028/13(R)]. We would also like to acknowledge NKEA Grant by Ministry of Agriculture Malaysia (304/CIPPM/650736/k123) and Universiti Sains Malaysia for providing funding through a University Grant (RUT 1001/PFARMASI/851001).

\section{Disclosure}

All the authors of the manuscript declare that there is no conflict of interest.

\section{References}

[1]. Adeyemo, O. A., \& Farinmade, A. E. (2016). Genotoxic and cytotoxic effects of food flavor enhancer, monosodium glutamate (MSG) using Allium cepa assay. African Journal of Biotechnology, 12(13).

[2]. Apak, R., Özyürek, M., Guclu, K., \& Capanoglu, E. (2015). Antioxidant activity/capacity measurement: III. Reactive oxygen and nitrogen species (ROS/RNS) scavenging assays, oxidative stress biomarkers, and chromatographic/chemometric assays. Journal of agricultural and food chemistry.

[3]. Araujo, C., \& Leon, L. (2001). Biological activities of Curcuma longa L. Memorias do Instituto Oswaldo Cruz, 96(5), 723-728.

[4]. Balmain, A., \& Yuspa, S. H. (2014). Milestones in skin carcinogenesis: the biology of multistage carcinogenesis. Nature Milestones, E2-E7.

[5]. Balmus, G., Karp, N. A., Ng, B. L., Jackson, S. P., Adams, D. J., \& McIntyre, R. E. (2015). A high-throughput in vivo micronucleus assay for genome instability screening in mice. Nature protocols, 10(1), 205-215.

[6]. Casolari, D. A., \& Melo, J. V. (2015). Chronic Myeloid Leukaemia Chromosomal Translocations and Genome Rearrangements in Cancer (pp. 107-138): Springer. 
[7]. Celik, T. A. (2012). Potential genotoxic and cytotoxic effects of plant extracts. A Compendium of Essays on Alternative Therapy, 233-250.

[8]. Chaudhary, P., Bhadana, U., Singh, R., \& Ahuja, A. (2015). Primary hepatic angiosarcoma. European Journal of Surgical Oncology (EJSO), 41(9), 1137-1143.

[9]. Chen, X.-W., B Sneed, K., Pan, S.-Y., Cao, C., R Kanwar, J., Chew, H., \& Zhou, S.-F. (2012). Herb-drug interactions and mechanistic and clinical considerations. Current drug metabolism, 13(5), 640-651.

[10]. Chhokar, V., \& Tucker, A. L. (2003). Angiogenesis: basic mechanisms and clinical applications. Paper presented at the Seminars in Cardiothoracic and Vascular Anesthesia.

[11]. Cummins, P., Harrity, C., Walsh, D., \& Marron, K. (2015). Male Infertility and Klinefelter Syndrome (47, XXY). J Clin Case Rep, 5(641), 2.

[12]. Dixit, A., Potaliya, P., \& Dixit, S. G. (2015). Karyotyping: Don't Banish it yet from the Field of Cytogenetics. Indian Journal of Genetics and Molecular Research, 4(2), 67. e Silva, C. R., Borges, F. F. V., Bernardes, A., Perez, C. N., e Silva, D. d. M., \& ChenChen, L. (2015). Genotoxic, Cytotoxic, Antigenotoxic, and Anticytotoxic Effects of Sulfonamide Chalcone Using the Ames Test and the Mouse Bone Marrow Micronucleus Test. PloS one, 10(9), e0137063.

[13]. Escaramís, G., Docampo, E., \& Rabionet, R. (2015). A decade of structural variants: description, history and methods to detect structural variation. Briefings in functional genomics, 14(5), 305-314.

[14]. Firbas, P., \& Amon, T. (2014). Chromosome damage studies in the onion plant Allium cepa L. Caryologia, 67(1), 25-35.

[15]. Food, U., \& Administration, D. (2000). Toxicological principles for the safety assessment of food ingredients. Redbook.

[16]. Fragouli, E., \& Delhanty, J. (2013). The Origins of Aneuploidy in Human Embryos Human Gametes and Preimplantation Embryos (pp. 107-124): Springer.

[17]. Genuis, S. J., Schwalfenberg, G., Siy, A.-K. J., \& Rodushkin, I. (2012). Toxic element contamination of natural health products and pharmaceutical preparations. PloS one, 7(11), e49676.

[18]. Giovinazzo, G., \& Grieco, F. (2015). Functional Properties of Grape and Wine Polyphenols. Plant Foods for Human Nutrition, 70(4), 454-462.

[19]. Gold, J., Li, Y., Shipley, N., \& Powers, P. (1990). Improved methods for working with fish chromosomes with a review of metaphase chromosome banding. Journal of Fish Biology, 37(4), 563-575.

[20]. Hoffman, R. (2014). EGCG: Potent extract of green tea. Intelligent Medicine. Jiménez, J., Gallo, D., Pachajoa, H., Carrillo, E., Cifuentes, R., \& Valderrama, A.

[21]. (2016). Prenatal diagnosis of trisomy 21 and semilobar holoprosencephaly. Presentation of a rare association. International Medical Review on Down Syndrome.

[22]. Kang, S. H., Kwon, J. Y., Lee, J. K., \& Seo, Y. R. (2013). Recent advances in in vivo genotoxicity testing: prediction of carcinogenic potential using comet and micronucleus assay in animal models. Journal of cancer prevention, 18(4), 277-288.

[23]. Kirsch-Volders, M., Sofuni, T., Aardema, M., Albertini, S., Eastmond, D., Fenech, M., . . Morita, T. (2003). Report from the in vitro micronucleus assay working group. Mutation Research/Genetic Toxicology and Environmental Mutagenesis, 540(2), 153-163. Lenzi, P., Bocci, G., \& Natale, G. (2016). John Hunter and the origin of the term "angiogenesis". Angiogenesis, 1-2.

[25]. Li, P., Xu, F., \& Shu, W. (2016). The Spectrum of Cytogenomic Abnormalities in Patients with Developmental Delay and Intellectual Disabilities. North American Journal of Medicine and Science, 8(4).

[26]. Lin, C.-K., Chang, Y.-Y., Wang, J.-D., \& Lee, L. J.-H. (2015). Increased standardised incidence ratio of malignant pleural mesothelioma in Taiwanese asbestos workers: A 29-year retrospective cohort study. BioMed research international, 2015.

[27]. Manshian, B. B., Singh, N., \& Doak, S. H. (2013). The in vitro micronucleus assay and kinetochore staining: methodology and criteria for the accurate assessment of genotoxicity and cytotoxicity. Genotoxicity Assessment: Methods and Protocols, 269-289.

[28]. Milner, J. (2004). Molecular targets for bioactive food components. The Journal of Nutrition, 134(9), 2492S-2498S.

[29]. Mitchison, T., \& Salmon, E. (2001). Mitosis: a history of division. Nature cell biology, 3(1), E17-E21.

[30]. Munné, S. (2006). Chromosome abnormalities and their relationship to morphology and development of human embryos. Reproductive biomedicine online, 12(2), 234-253.

[31]. Natarajan, A. T. (2002). Chromosome aberrations: past, present and future. Mutation Research/Fundamental and Molecular Mechanisms of Mutagenesis, 504(1), 3-16.

[32]. Ngulde, S. I., Sandabe, U. K., \& Hussaini, I. M. (2015). Ethnobotanical survey of anticancer plants in Askira/Uba local government area of Borno State, Nigeria. African Journal of Pharmacy and Pharmacology, 9(5), 123-130.

[33]. Oecd. (1994). OECD Guidelines for the Testing of Chemicals: Organization for Economic.

[34]. Oga, E. F., Sekine, S., Shitara, Y., \& Horie, T. (2015). Pharmacokinetic Herb-Drug Interactions: Insight into Mechanisms and Consequences. European journal of drug metabolism and pharmacokinetics, 1-16.

[35]. Palomaki, G. E., Deciu, C., Kloza, E. M., Lambert-Messerlian, G. M., Haddow, J. E., Neveux, L. M., . . Grody, W. W. (2012). DNA sequencing of maternal plasma reliably identifies trisomy 18 and trisomy 13 as well as Down syndrome: an international collaborative study. Genetics in medicine, 14(3), 296-305.

[36]. Persano, L., Zagoura, D., Louisse, J., \& Pistollato, F. (2015). Role of Environmental Chemicals, Processed Food Derivatives, and Nutrients in the Induction of Carcinogenesis. Stem cells and development, 24(20), 2337- 2352.

[37]. Purushothaman, A., Reghu, R., \& Vijayan, M. (2015). ENVIRONMENTAL AND OCCUPATIONAL RISK FACTORS ASSOCIATED WITH LUNG CANCER.

[38]. Schaaf, C. P., Zschocke, J., \& Potocki, L. (2011). Human Genetics: from molecules to medicine: Lippincott Williams \& Wilkins.

[39]. Screening, P., \& Board, P. E. (2015). Skin Cancer Prevention (PDQ®).

[40]. SERT ZAYIF, S., \& UZ, E. (2016). Traditional Medicinal Plants Used in Turkey and Their Anti-Cancer Effects. International Journal of Health and Nutrition, 7(1), 1-19.

[41]. Shaffer, L. G., McGowan-Jordan, J., \& Schmid, M. (2013). ISCN 2013: an international system for human cytogenetic nomenclature (2013): Karger Medical and Scientific Publishers.

[42]. Sheth, F., Sheth, H., Pritti, K., Tewari, S., Desai, M., Patel, B., \& Sheth, J. (2014). Evolution of Cytogenetics in Disease Diagnosis. Journal of Translational Toxicology, 1(1), 3-9.

[43]. Singh, C. K., Siddiqui, I. A., El- Abd, S., Mukhtar, H., \& Ahmad, N. (2016). Combination chemoprevention with grape antioxidants. Molecular nutrition \& food research.

[44]. SRINIVASAN, R. (2014 ). NATUREVOLUTION EFFECTIVE AGAINST CANCER THERAPY- REVIEW (TREATING CANCER DISEASES USING PLANT PRODUCTS) Int J Pharm Bio Sci, 5 (2), 357 - 365.

[45]. Tal, R., Schwartz, Y., Zolotushko, J., \& Lorber, A. (2014). Trisomy 13 (Patau syndrome) with tetralogy of Fallot-To treat or not to treat? International journal of cardiology, 172(1), e175-e176.

[46]. Valenti, D., de Bari, L., De Filippis, B., Henrion-Caude, A., \& Vacca, R. A. (2014). Mitochondrial dysfunction as a central actor in 
intellectual disability-related diseases: An overview of Down syndrome, autism, Fragile X and Rett syndrome. Neuroscience \& Biobehavioral Reviews, 46, 202-217.

[47]. Visscher, K., Metcalfe, K. A., \& Semple, J. L. (2015). Breast deformity and reconstruction in Turner syndrome: A collection of case studies. JPRAS Open, 4, 16-21.

[48]. Vodenkova, S., Polivkova, Z., Musak, L., Smerhovsky, Z., Zoubkova, H., Sytarova, S., . . . Jiraskova, K. (2015). Structural chromosomal aberrations as potential risk markers in incident cancer patients. Mutagenesis, 30(4), 557-563.

[49]. Vorsanova, S., Yurov, Y., Soloviev, I., \& Iourov, I. (2010). Molecular cytogenetic diagnosis and somatic genome variations. Current genomics, 11(6), 440- 446.

[50]. Zulkipli, I. N., David, S. R., Rajabalaya, R., \& Idris, A. (2015). Medicinal plants: a potential source of compounds for targeting cell division. Drug target insights, 9, 9. 